\title{
Sürdürülebilirlik Raporlamasında Paydaş Katılımı: Türkiye’deki Firmaların Analizi
}

\section{Çimen KARATAŞ ÇETİN ${ }^{1}$ Seçil VARAN ${ }^{2}$ Cemile SOLAK FIŞKIN ${ }^{3}$}

\section{ÖZET}

Bu çalışmanın amacı, Türkiye'de faaliyet gösteren firmaların kurumsal sosyal sorumluluk ve sürdürülebilirlik raporlarının, paydaş yönetimi ve paydaş katılımı açısından incelenmesidir. $\mathrm{Bu}$ amaçla, Türkiye'de faaliyet gösteren firmaların, Küresel Raporlama Girişimi standartlarına uygun olarak hazırladığı ve 2012-2013 yıllarında yayınlanan kurumsal sosyal sorumluluk ve sürdürülebilirlik raporları, içerik analizi yöntemi ile analiz edilmiştir. Çalışmanın bulguları; incelenen raporların paydaşlar ile ilgili açıklamalarda paydaş yönetimi kavramını ön planda tuttuğunu, ancak paydaş katılımı ile ilgili açıklamaların yetersiz olduğunu göstermektedir. Çalışmanın sonuçları; sürdürülebilirlik raporlarının hazırlanma sürecinde firmaların, bu raporlarda öncelikli olarak açıklanacak olan bilgileri paydaş katılımı ile belirlemelerinin önemini ortaya koymaktadır.

Anahtar Kelimeler: Sürdürülebilirlik Raporlaması, Paydaş Yönetimi, Paydaş Katılımı, Önceliklendirme. 


\title{
Stakeholder Engagement in Sustainability Reportting:
}

\section{Analysis of the Companies in Turkey}

\begin{abstract}
The aim of this study is toanalyzethecorporatesocialresponsibilityandsustainabilityreports of companies operating in Turkey,with regards to stakeholder management and stakeholder engagement. For this purpose, the corporate social responsibility and sustainability reports of companies operating in Turkey that are prepared according to the standards of the Global Reporting Initiative and published in 2012 - 2013were investigated using content analysis method. The findings show that the companies disclose the practices of stakeholder management extensively; however disclosures regarding stakeholder engagement are insufficient. The results reveal the significance of stakeholder engagement in determining the material information to be disclosed in sustainability reporting.
\end{abstract}

Keywords: Sustainability Reporting, Stakeholder Management, Stakeholder Engagement, Materiality.

\section{GíRiş}

Günümüz iş çevresi, işletmelerin paydaşları ile etkileşiminin giderek artan önemini ortaya koymakta ve işletmeleri sosyal sorumluluk bilinci çerçevesinde hareket etmeye yöneltmektedir. Paydaş teorisi; şirketlerin kar maksimizasyonu ve hissedarlara değer yaratma amaçlarını genişletmiş, hissedarlar dışındaki diğer paydaşlar için de değer yaratılması gerekliliğini ortaya koymuştur (Longo vd., 2005). Bu teoriye göre bir işletmenin amacı, tüm paydaşlar için değer yaratmak ve bu değeri maksimize etmektir.

Kurumsal sosyal sorumluk ve sürdürülebilirlik raporları, paydaşlar için yaratılan değerin, finansal ve finansal olmayan açıklamalarla ifade edildiği raporlardır.Dünyada yaygın olarak kabul görmüş uluslararası sürdürülebilirlik raporlama çerçevesini sunan Küresel Raporlama 
Girişimi Sürdürülebilirlik Raporlama Rehberi (Global Reporting Initiative-GRI)'nin www.globalreporting.org adresinden ulaşılabilen web sitesinde, Kurumsal sosyal sorumluluk ve sürdürülebilirlik raporları; "ekonomik, çevresel, sosyal ve yönetişim performans bilgilerinin açıklandı̆̆ı, kurumun sürdürülebilirlik kapsamındaki olumlu ve olumsuz etkilerinin iletişiminin yapıldı $\breve{l}$ ve şirket politikası, stratejisi ve operasyonlarını etkileyen bilgilerin devamlı aktarıldı ̆̆ raporlar” şeklinde tanımlanmaktadır.

Sürdürülebilirlik raporlarında yer alan açıklamalar, paydaşların değerlendirmeleri ve kararları üzerinde etkisi olabilecek öncelikli (material) konuları ve göstergeleri kapsamalıdır (GRI, 2010:9). Bu nedenle, sürdürülebilirlik raporları hazırlama sürecinde paydaş katılımı, hangi bilgilerin öncelikli olarak raporlanacağını belirleyebilmek için gereklidir. Sürdürülebilirlik raporlarının hazırlanma sürecinde, özellikle finansal olmayan bilgilerin raporlanmasında, “paydaş yönetimi” ile "paydaş katılımı” kavramlarının ve “önceliklendirme” ilkesinin ön plana çıktığı görülmektedir.

Paydaş yönetimi, şirketlerin kilit paydaşlarının belirlenmesi ve belirlenen paydaşların beklentilerine, isteklerine, ihtiyaçlarına göre şekillenen örgütseldavranış olarak tanımlanmakta olup; paydaş katılımı ise, paydaşların şirket yönetimi ile ilgili "karar alma sürecine dâhiledilmesi"dir (Manetti, 2011:111).

Bu çalışmanın amacı, Türkiye'de faaliyet gösteren firmaların kurumsal sosyal sorumluluk ve sürdürülebilirlik raporlarının, paydaş yönetimi ve paydaş katılımı açısından incelenmesidir. $\mathrm{Bu}$ amaçla, Türkiye'de faaliyet gösteren işletmelerin yayınladığı ve Küresel Raporlama Girişimi standartlarına uygun olarak hazırlanan kurumsal sosyal sorumluluk ve sürdürülebilirlik raporları, içerik analizi yöntemi ile analiz edilmiştir. Önceki çalışmalarda, Türkiye'de faaliyet gösteren işletmelerin paydaş katılımı uygulamaları ile ilgili çok az sayıda bulgunun olması ve sürdürülebilirlik raporlarının hazırlanmasında paydaş katılımının artan önemi nedeniyle, çalışmanın bulgularının, kurumsal sosyal sorumluluk ve sürdürülebilirlik 
konusunda yapılan araştırmalara ve uygulayıcıların sürdürülebilirlik raporlarını hazırlama sürecine katkı sağlayacağı düşünülmektedir.

Çalışmanın ikinci bölümünde önceki çalışmaların bulguları sunulmuştur. Üçüncü bölümde ise Küresel Raporlama Girişimi standartları ile ilgili bilgi verilmektedir. Dördüncü bölümde çalışmanın yöntemi ve bulguları, son bölümde ise sonuçları yer almaktadır.

\section{2.ÖNCEKİ ÇALIŞMALAR}

Paydaş kavramı Edward Freeman (1984)'ın “ Strategic Management: A Stakeholder Approach" adlı çalışmasının ardından yaygın kabul kazanmış ve bu kavram ile ilgili birçok çalışma yapılmıştır (Preble, 2005:110). Freeman ve Reed (1983)'e göre "geniş anlamıyla paydaşlar, bir örgütün amaçlarını gerçekleştirmesini etkileyen ya da gerçekleşen bu amaçlardan etkilenen tüm grup ve bireyleri kapsar (kamu çıkar grupları, protesto grupları, hükümet kuruluşları ve temsilcileri, ticaret kuruluşları, rakipler, sendikalar, çalışanlar, müşteriler, hisse sahipleri, vd.). Daha dar anlamda ise, paydaşlar; örgütün varlı̆̆ını sürdürebilmesi için bağımlı olduğu tüm grup ve bireyleri kapsamaktadır (çalışanlar, müşteriler, tedarikçiler, hükümet kuruluşları ve temsilcileri, hisse sahipleri, finansal kuruluşlar, vd.)" (Gürol vd, 2010: 146).

Paydaş teorisi araştırmacıları, kurumsal sosyal sorumluluk, paydaş yönetimi ve paydaş katılımı kavramlarını bağdaştırmaktadır (Huijsteeve Glasbergen, 2008:298; Matris, 2007:366). Paydaş teorisi kurumsal sosyal sorumluluk kavramının ayrılmaz bir parçası olmuştur (Matris, 2007:366). Paydaş yönetimi, şirketlerin paydaşlarının beklentilerini, isteklerini, ihtiyaçlarını tatmin edebilecek örgütsel davranış olarak tanımlanmaktadır (Manetti,2011:111). Paydaş katılımı kavramı ise, kurumsal sosyal sorumluluğun eyleme geçirilmesi ve raporlanması konusunda ön plana çıkmaktadır (Greenwood, 2007:315). Kısaca paydaşların şirket yönetimi ile ilgili "karar alma sürecine dâhil edilmesi” (Manetti, 2011: 111) olarak ifade edilen paydaş katılımı, şirketler ve paydaşlar arasındaki işbirliği ve anlayışı 
arttırmayı amaçlayan ilişki yönetimi süreci olarak da tanımlanabilir (GableveShireman, 2005:9). Şirketler tarafindan hem gereklilik hem de bir firsat olan (QuinnveDalton, 2009:31) paydaş katılımı, aynı zamanda kaliteli sürdürülebilirlik raporlaması için bir anahtar olarak görülmektedir (Moneva vd.,2006:107).

Uluslararası literatürde paydaş yönetimi ve paydaş katılımı ile ilgili çok sayıda bilimsel araştırma yapılmış ve bu kavramlar değişik boyutlarda tartı̧̧1mış̧ır. Ulusal literatürde ise paydaş katılımı ile ilgili çalışmalar oldukça yeni ve sınırlıdır. Bu başlık altında yalnızca paydaş katılımı ile ilgili literatüre yer verilecek ve özellikle sürdürülebilirlik raporlamasını konu alan çalışmalara değinilecektir.

Belal (2002:24), AA1000 Paydaş Katılımı Standardı değerlendirme aracını kullanarak Sosyal ve Etik Muhasebe, Denetim ve Raporlama (SocialAndEthical Accounting, Auditing andReporting) uygulamalarının ideal paydaş katılımını desteklemediğini, daha çok paydaşları etkili olarak yönetmeyi meşrulaştırma aracı olarak gördüklerini ortaya çıkartmıştır. Ayrıca Belal ve Owen (2007:472), 23 Bangladeş şirketi ile görüşmeler gerçekleştirmiş ve yaptıkları çalı̧̧a sonucunda varolan raporlama uygulamalarının temel motivasyonununpaydaş katılımdan ziyade, şirket yönetiminin daha büyük paydaş gruplarını yönetme arzusundan kaynaklandığını ortaya koymuşlardır.

Prado-Lorenzo vd. (2009:94), 116 İspanyol şirketi üzerinde Küresel Raporlama Girişimi (GRI) raporları ile yaptığı araştırmada, bazı paydaşların şirketin stratejik imajı ile birlikte sürdürülebilirlik raporlarının yayınlanmasında etkisi olduğu hipotezini destekleyici bulgulara ulaşmış, fakat ekonomik performans ile paydaş katılımı süreci arasında bir ilişki bulamamıştır. Mio ve Venturelli (2012:340) ise borsaya kote edilmiş 50 İtalyan ve İngiliz şirketinin yıllık raporlarını karşılaşıırmış ve benzer sonuçlara ulaşmıştır.

Skouloudisvd. (2012:16) havaalanlarının yayınlanan sürdürülebilirlik raporlarının kapsamlılığını paydaş katııımı kavramını da göz önünde bulundurarak içerik analizi yöntemi 
ile incelemiş ve sürdürülebilirlikraporlamasının ulusal, yasal ve politik faktörlere göre şekillendiğini ortaya koymuştur.

Manetti veToccafondi (2014:35) ise içerik analizi yöntemi ile kar amacı gütmeyen örgütlerin sürdürülebilirlik raporlamalarında paydaş katılımının rolünü araştırmıştır. Araştırma, sürdürülebilirlik raporlarının hazırlanmasında paydaş katılımının rolünü, katılımın ne ölçüde etkin olduğunu ve paydaş yönetimi özelliklerinin ne ölçüdedahil edildiğini ortaya koymayı amaçlamıştır. $\mathrm{Bu}$ amaç doğrultusunda raporlamanın kalitesinin önceliklendirmeilkesi açısından düşük olduğu ve etkin paydaş katılımından çok, paydaş yönetimi temelli olduğu ortaya konmuştur.

Manetti (2011:115) paydaş katılımının kalitesinin araştırılması amacıyla içerik analizi yöntemi ile görgül bir çalışma gerçekleştirmiştir. Manetti (2011), Belal (2002) ile benzer sonuçlara ulaşmış ve sürdürülebilirlik raporlamasının, şirketlerin ideal olan paydaş katılımını uygulamaktan çok, bunu paydaşları etkin olarak yönetebilmek için meşrulaştırma aracı olarak gördüklerini ortaya çıkarmıştır.

Türkiye'de ise paydaş yönetimi ve paydaş katılımı ile ilgili kısıtlı sayıda çalışma gözlemlenmiştir. Bu konu ile ilgili olarak Özalp vd. (2008:70), İktisadi ve İdari Bilimler Fakülteleri öğrencilerinin sosyal sorumluluk algılamalarını ortaya koymak amacıyla gerçekleştirdiği çalışmalarında öğrencilerin gelecekte önemli birer paydaş olacağını belirtmişler ve paydaş ve paydaş yönetimi kavramlarına geniş yer vermişlerdir. Temizel vd. (2010:1) çalışmalarında işletmelerin finansal paydaşlarla ilişkisi ve bu ilişkide işletmelerin internetsitelerinin önemi üzerinde durarak İMKB Ulusal-50 endeksinde yer alan işletmelerin internet sitelerini incelemişlerdir. Tak (2009), işletmelerin sosyal sorumluluk ve paydaş grupları ile ilişkilerinin yönetimi konusunda yazdığı kitabında, Türkiye'deki bankaların finansal raporlarını içerik analizi yöntemiyle inceleyerek öne çıkan paydaş gruplarını belirlemiştir. Becan (2011:16) ise çalışmasında, Türkiye'de finans sektöründe faaliyet 
gösteren 5 önemli kuruluşun (Garanti Bankası, Türkiye İş Bankası, Yapı Kredi Bankası, Denizbank ve Türk Ekonomi Bankası) kilit paydaşlarıyla iletişim amacıyla, kurumsal sosyal sorumluluğu basın bültenlerinde ne derece kullanabildiğini karşılaştırmalı olarak ortaya koymaktadır. Toplumsal faaliyetlere, diğer kurumsal sosyal sorumluluk alanlarına kıyasla oldukça önem verildiğini; sosyal topluluk/çevre ve müşterilerin kurumsal sosyal sorumluluk mesajların ileten basın bültenlerinin en fazla hedeflediği paydaş grupları olduğunu ortaya koymuştur. Altuntaş ve Türker (2012:54), paydaş ve paydaş yönetimi olgularının Türk işgörme anlayışı içerisinde kabul gören kavramlar olmaya başladığını belirtmişlerdir. Paydaş katılımı ile ilgili olarak ise, Evliyaoğlu ve Hemedoğlu (2012:140) toplam kalite yönetimi uygulamalarının şirketlerin finansal olmayan performansları üzerindeki etkilerinin belirlenmesi amacıyla yaptıkları çalışmalarında, paydaş katılımını toplam kalite yönetimi uygulamalarındaki boyutlardan birisi olarak belirlemiş ve paydaş katılımınıninovasyon ve öğrenme perspektifi üzerinde anlamlı bir etkisi olmadığını ortaya koymuştur.

\section{KÜRESEL RAPORLAMA GİRIŞiMII SÜRDÜRÜLEBILLİRLIKK RAPORLAMA REHBERI (GRI)}

Uluslararası kabul görmüş rehberler, birçok ülkede zorunlu olmayan ve gönüllülük esasına göre hazırlanan sürdürülebilirlik raporlarında bulunan açıklamaların, erişilebilir ve karşılaştırılabilir olmasını sağlamaktadır (GRI， 2014). Küresel Raporlama Girişimi Sürdürülebilirlik Raporlama Rehberi (Global ReportingInitiative - GRI) Amerika'da bulunan, kâr amacı gütmeyen ve bağımsız bir kuruluş olan Küresel Raporlama Girişimi tarafindan geliştirilmiştir. Küresel Raporlama Girişimi (GRI) Birleşmiş Milletler, çeşitli sektörlerden temsilciler, muhasebe meslek mensupları ve kâr amacı gütmeyen bazı kurumların işbirliği ile oluşturulmuştur (Ulusan, 2009:186). GRI Rehberi, dünyada en çok kabul görmüş uluslararası sürdürülebilirlik raporlama çerçevesini sunmaktadır (KPMG, 2008:16; Ulusan, 2009:192). 
GRI'nınmisyonu, küresel olarak uygulanabilir bir "Sürdürülebilirlik Raporlaması Rehberi” geliştirmek ve finansal raporlama gibi rutin ve karşılaştırılabilir hale getirerek yaygınlaştırmaktır. Bu rehber, şirketlerin kendi istekleriyle hazırlayacakları, sürdürülebilirlik ile ilgili çevresel, ekonomik ve sosyal faaliyetlerini ve bu faaliyetlerin sonuçlarını raporlayabilecekleri bir çerçeve sunmaktadır. Kuruluşun vizyonu ise; kurumların ekonomik, çevresel, sosyal ve yönetişim performanslarını ve etkilerini sorumlu bir şekilde yönettikleri ve şeffaf bir şekilde raporladıkları sürdürülebilir küresel bir ekonomidir.

GRI, uygulayıc1lara sunduğu Sürdürebilirlik Raporlamas1 rehberlerini G1, G2, G3, G3.1 ve G4 başlıklarıyla güncellemiştir. Araştırma sorusu yanıtlanırken, GRI raporlarının bir önceki versiyonu olan G3.1 raporlarından yararlanılacaktır. G4 ${ }^{1}$ raporları rehberleri Mayıs 2013'te yayımlanmış ve uygulamaya konmuştur.

G3 rehberinin amacı, küresel sürdürülebilirlik programına katkıda bulunmak ve dünya toplumuna sürdürülebilirlik performanslarını açıklamak isteyen şirketler için küresel bir rehber sunmaktır.Sürekli geliştirilen rehberin, G3.1 versiyonu 2010'da kullanılmaya başlanmış olup, 2013'te GRI'nin Amsterdam'daki 4. Küresel konferansında 2016 yılı başından itibaren kullanılmak üzere, G4 versiyonu tanıtılmıştır.

GRI G3.1 versiyonuna göre, sürdürülebilirlik raporlaması içeriği;önceliklendirme, paydaş katılımı, sürdürülebilirlik çerçevesi ve bütünlük ilkelerine göre belirlenir.Açıklamalar, sürdürülebilirlik çerçevesi ve önceliklendirme (materiality) ilkesine göre,paydaşların karar vermede kullanabileceği şekilde raporlanır. Bu bilgiler, kurumun önemli ekonomik, çevresel ve sosyal etkilerini yansıtan veya paydaşların değerlendirmeleri ve kararları üzerinde önemli etkisi olabilecek konuları ve göstergeleriönceliklendirerek kapsamalıdır (GRI, 2010; GRI 2011).

${ }^{1}$ GRI G4 raporlamasının Mayıs 2013'te uygulamaya konması nedeniyle, örneklemde bulunan şirketler GRI G3.1 formatını kullanmaktadır. 
Paydaş katılımı, neyin öncelikli olarak raporlanacağını belirleyebilmek adına ön plana çıkmaktadır. Paydaş katılımı konusunda GRI uygulama rehberlerine göreişletme, paydaşlarının kimler olduğunu belirlemeli ve raporunda onların makul beklenti ve menfaatlerine ne şekilde yanıt verdiğini açıklamalıdır.

Paydaş katılımı süreçlerinin raporlama amacıyla kullanılması venasıl kullanıldığının açıklanması, karar verme ile ilgili öncelikli bilgilerin belirlenmesi ve açıklanmasında yararlıdır. Bu açıklamalar, sistematik veya genel kabul görmüş yaklaşımlara, yöntemlere veya ilkelere dayandırılmalıdır. Rapor hazırlayan kurum, hangi paydaşların katılımını sağladığııı, onların katılımını nasıl ve ne zaman sağladığını, katılımın rapor içeriği ile kurumun sürdürülebilirlik faaliyetlerini nasıl etkilediğini tanımlamaya yönelik yaklaşımını belgelendirmelidir(GRI, 2010, GRI 2011). Daha sonra bütünlük ilkesine göre raporlanacak açıklamalar, kapsam ve süreç açısından değerlendirilir.

Tablo 1, GRI G3.1'e göre şirketlerin sürdürülebilirlik raporlarında paydaş katılımı ile ilgili yapmaları gereken açıklamalarımaddeler halinde göstermektedir.

Tablo 1:GRI G3.1Paydaş Katılımı

4.14 Kurum tarafından katılımı sağlanan paydaş gruplarının listesi.

Paydaş gruplarının örnekleri şöyledir:

- Yerel halk,

- Sivil toplum,

- Müşteriler,

- Hissedarlar ve sermaye sağlayıcıları,

- Tedarikçiler,

- CÇalışanlar, diğer işçiler ve üye oldukları

- $\quad$ Sendikalar. 
4.15 Katılım yapılacak paydaşların kimler olacağının belirlenmesi ve seçimlerine dair esas.

$\mathrm{Bu}$ madde, kurumun kendi paydaş gruplarını tanımlama ve birlikte katılım yapacak veya yapmayacak olduğugrupların tespiti sürecini de içerir.

4.16 Paydaş türü ve grubuna göre katılım sıklığı da dâhil, paydaş katılımı yöntemleri.

- $\mathrm{Bu}$, anketleri, hedef gruplarını, topluluk panellerini, kurumsal bilgilendirme panellerini, yazılı bildirimleri, yönetim/sendika yapılarını ve diğer araçları içerebilir.

- $\quad$ Kurum, rapor hazırlama sürecine özgü, herhangi bir katılımın sağlanıp sağlanmadığını belirtmelidir.

4.17 Paydaş katılımı ile ortaya konan başlıca konular ile kaygılar ve kurumun bunlara, yaptığı raporlamaaracılığıyla verdiği yanıt da dâhil, nasıl yanıt verdiği.

\section{Kaynak: GRI, 2010:25.}

Ayrıca,GRI Sürdürülebilirlik Raporlamasındafirmalar için üçseviye bulunmaktadır. Bunlar C, B ve A olarak sınıflandırılmaktadır.Her seviyede yer alan rapor hazırlama ölçütleri GRIRaporlama Çerçevesinin uygulaması veya kapsamındakiartışı yansıtır. Eğer kurum, raporu hazırlama sürecinde bağımsız dışdenetimden geçmiş ise, her seviye için bir artıyı (+) kendi kendine beyan edebilir. Kurum, raporlama seviyesini bağımsız bir denetim kuruluşu ve /veya GRI denetimi ile destekleyerek kendisi beyan eder.

\section{AMAÇ VE YÖNTEM}

\subsection{Araştırmanın Amacı ve Örneklemi}

Çalışmanın amacı, Türkiye'de faaliyet gösteren firmaların kurumsal sosyal sorumluluk ve sürdürülebilirlik raporlarının, paydaş yönetimi ve paydaş katılımı açısından incelenmesidir. Bu amaç doğrultusunda, Türkiye'de faaliyet gösteren firmaların, Küresel Raporlama Girişimi (GRI) standartlarına uygun olarak hazırladığı kurumsal sosyal sorumluluk ve sürdürülebilirlik 
raporlarına Küresel Raporlama Girişimi (GRI) internet sitesinden ulaşılmışırı. İngilizce ve Türkçe olarak hazırlanan, 2012-2013 yıllarında yayınlanan ve GR3, GR3.1. seviyesi raporlar seçilmiş ve 41 firmanın raporlarına ulaşılmıştır. Örneklemin daraltılmaması amacıyla Manetti (2011) çalışmasının aksine firmalar raporların GRI uygulama seviyelerine göre sınırlandırılmamıştır. $\mathrm{A}+, \mathrm{A}, \mathrm{B}+, \mathrm{B}, \mathrm{C}$ gibi tüm GRI uygulama seviyelerindeki raporlar örnekleme dâhil edilmiştir. Belirlenen 41 firma içerisinden; 10'unun grup şirketi olması ve 1'inin format olarak incelemeye elverişsiz olması nedeniyle 11 firma örneklem dışında tutularak toplamda 30 firmanın raporları analize tabi tutulmuştur. 30 rapordan 26'sının sürdürülebilirlik raporu, 4'ünün ise kurumsal sorumluluk raporu olduğu tespit edilmiştir. Bunun yanında, 25 raporun İngilizce, 5 raporun (3 sürdürülebilirlik raporu ve 2 kurumsal sorumluluk raporu) ise Türkçe olarak hazırlandığı görülmüştür.

\subsection{Araştırmanın Yöntemi}

Araştırma yöntemi olarak sürdürülebilirlik raporlarını inceleyen çalışmalarda yaygın olarak kullanılan (Altuntaş ve Türker, 2012; Manetti, 2011; Tak, 2009) içerik analizi kullanılmıştır. Toplamda 30 adet ve 2617 sayfa rapor analize tabi tutulmuştur. İçerik analizi; bir metnin sistematik, tarafsız ve sayısal olarak analiz edilmesini ifade eden, metinden sonuçlar çıkarmak için gerçekleştirilen bir dizi usulü içeren bir araştırma yöntemidir (Özdaşlı ve Çelikkol, 2012: 145; Wimmer ve Dominick, 2000:135-136). Gökçe (2006)'nin belirttiği gibi içerik analizi sürecinde öncelikli olarak araştırma soruları belirlenmiş, örneklem saptanmış, kategori sistemi oluşturularak kodlama ve analiz birimleri seçilmiş̧ir.Paydaş yönetimi ve katılımı konusunda gerçekleştirilen Manetti (2011) ve Tak (2009) çalışmalarında kullanılan iki farklı tür içerik analizi bu araştırmada da uygulanmıştır. Tak (2009) çalışmasıyla paralel olarak temel paydaş grupları; müşteri, rakip, dağıtıcı, çalışan, tedarikçi, toplum, hissedar, medya, sivil toplum kuruluşu (STK), hükümet, paydaş ve çevre olarak belirlenmiş ve her bir sözcügü̈n ve benzer anlama gelecek sözcüklerin raporlarda kaç defa geçtiği analiz edilmiştir. Bu anlamda içerik 
analizi tekniklerinden, birim veya öğelerin sayısal ve yüzdesel görünme sıklığını ortaya koyan (Bilgin, 2006) frekans analizi tekniği kullanılmıştır. İkinci olarak ele alınan içerik analizinde ise Manetti (2011) çalışmasından yola çıkılmış, ancak bu çalışmanın kapsamı ve amacına uygun olarak aşağıda listelenen araştırma alt soruları yeniden düzenlenmiş ve buna uygun kategoriler oluşturulmuştur.

- $\quad$ Rapor içerisinde paydaş katılımı bölümünün mevcut olup olmadığı ve paydaş katılımının amaç ve hedeflerinin ne olduğu

- $\quad$ Rapor içerisinde belirtilmiş olan paydaş grupları

- $\quad$ Paydaş gruplarının raporlama içerisinde temsil edilme düzeyi

- $\quad$ Paydaşların raporlama sürecine katılımlarının düzeyi (sadece bilgi sağlama ile katılım, rapora ilişskin eleştirilerinin dikkate alınması, vb.)

- $\quad$ Paydaş katılımını sağlamada kullanılan kanallar ve yöntemler (çalıştaylar, odak grupları, dönemsel toplantılar, paneller, vb.)

- $\quad$ Paydaş katılımı konusunda yaşanan sıkıntıların belirtilip belirtilmediği

- $\quad$ Paydaş katılımının belirli prensipler çerçevesinde sağlanıp sağlanmadığı

- $\quad$ Raporlarda AA1000 Paydaş Katılımı Standard'ına yer verilip verilmediği

- $\quad$ Raporlamada önceliklendirme (sürdürülebilirlik konuları) matrislerine yer verilip verilmediği

- $\quad$ GRI Uygulama seviyeleri

- $\quad$ GRI G3.1 Paydaş Katılımı yeterliliklerini karşılama düzeyleri

Belirtilen araştırma konularına cevap bulabilmek amacıyla örneklemdeki 30 işletmenin sürdürülebilirlik ve kurumsal sosyal sorumluluk raporları ayrıntılı olarak incelenmiş ve frekansları hesaplanmıştır. Bireysel hataların önlenmesi amacıyla içerik analizi sürecinde üç araştırmacı beraber çalışmıştır. 


\section{BULGULAR}

Araştırma bulgularında öncelikli olarak incelenen 30 firmaya ilişkin genel bilgiler sunulmaktadır. Tablo 2, örneklemde bulunan 30 firmanın sektörel dağılımını göstermektedir. Tablo 2'ye göre örneklemde en fazla finansal hizmetler sunan firmalar bulunmakta olup, sağlık ürünleri ve enerji sektörleri ikinci sırada yer almaktadır. Diğer sektörleri ise sırasıyla yiyecek-içecek (n:3), otomotiv (n:3), ulaştırma ve lojistik (n:2), telekomünikasyon ve haberleşme (n:2), tekstil (n:1), yapı malzemeleri (n:1), dayanıklı tüketim malları (n:1), havacılık (n:1) ve kimya (n:1) oluşturmaktadır.

Tablo 2: İncelenen Firmaların Sektörel Dağılımı

\begin{tabular}{lll}
\hline Sektörler & Firma Sayısı (n) & $\%$ \\
\hline Finansal Hizmetler & 7 & 23,3 \\
Sağlık Ürünleri & 4 & 13,3 \\
Enerji & 4 & 13,3 \\
Gıda (Yiyecek-İcecek) & 3 & 10,0 \\
Otomotiv & 3 & 10,0 \\
Ulaştırma ve Lojistik & 2 & 6,7 \\
Telekomünikasyon ve Haberleşme & 2 & 6,7 \\
Tekstil & 1 & 3,3 \\
Yapı Malzemeleri & 1 & 3,3 \\
Dayanıklı Tüketim Malları & 1 & 3,3 \\
Havacılık & 1 & 3,3 \\
Kimya & 1 & 3,3 \\
\hline TOPLAM & 30 & 100 \\
\hline
\end{tabular}


Tablo 3'de gösterildiği gibi incelenen firmaların GRI uygulama seviyeleri değişiklik göstermektedir. A+ seviyesinde 8 firma, A seviyesinde 6 firma, B+ seviyesinde 2 firma, B seviyesinde 8 firma ve C seviyesinde 6 firma mevcuttur. A+ ve A uygulama seviyesine sahip firmaların ağırlıkla enerji, sağlık ve finans sektöründe yer aldığı ortaya çıkmıştır.

Tablo 3: İncelen Firmaların GRI G3.1 Uygulama Seviyeleri

\begin{tabular}{llc}
\hline GRI Uygulama Seviyesi & Firma sayısı (n) & \% \\
\hline A+ & 8 & 26,7 \\
A & 6 & 20,0 \\
B+ & 2 & 6,7 \\
B & 8 & 26,7 \\
C & 6 & 20,0 \\
Toplam & 30 & 100,0 \\
\hline
\end{tabular}

Tablo 4 ile incelenen firmaların sürdürülebilirlik ve kurumsal sosyal sorumluluk raporlarında “paydaşlarımız, paydaş yönetimi veya paydaş katılımı” gibi ilgili bölümlerinde “GRI.4.14. Kurum tarafından katılımı sağlanan paydaş gruplarının listesi” kapsamında belirttikleri paydaşlar ve her bir raporda ne kadar yer aldığı görülmektedir. 
Tablo 4: İncelenen Firmalarca Belirtilen Paydaşlar

\begin{tabular}{|c|c|c|}
\hline Paydaşlar & Firma sayısı (n) & $\%$ \\
\hline *Müşteri & 29 & 96,7 \\
\hline *Tedarikçi & 28 & 93,3 \\
\hline *Çalışan & 28 & 93,3 \\
\hline *Sivil Toplum Kuruluşları (STK) & 25 & 83,3 \\
\hline *Hükümet/Kamu Kurumları & 25 & 83,3 \\
\hline *Toplum & 24 & 80,0 \\
\hline *Medya/Sosyal Medya & 22 & 73,3 \\
\hline *Hissedar & 19 & 63,3 \\
\hline *Yatırımcı & 13 & 43,3 \\
\hline *Bayi/Franchiser & 12 & 40,0 \\
\hline *Eğitim Kurumları & 11 & 36,7 \\
\hline *Dağıtıcı & 9 & 30,0 \\
\hline *Finans Kuruluşları & 8 & 26,7 \\
\hline *İştirakler & 8 & 26,7 \\
\hline *Rakip & 7 & 23,3 \\
\hline *Uluslararası Organizasyonlar & 6 & 20,0 \\
\hline *Endüstriyel/Ticari Birlikler/Sektörel Dernekler & 6 & 20,0 \\
\hline *Yerel Yönetimler & 6 & 20,0 \\
\hline *Düşünce Liderleri/Kanaat Önderleri & 3 & 10,0 \\
\hline *Üniversite Öğrencileri & 3 & 10,0 \\
\hline *Sendikalar & 3 & 10,0 \\
\hline *Çalışanların aileleri & 1 & 3,3 \\
\hline
\end{tabular}

Buna göre, paydaş olarak en çok kullanılan grup; müşteri $(\% 96,7)$ iken tedarikçi ve çalışan da raporların \%93,3'ünde paydaş olarak belirtilmiştir. STK'lar ve hükümet/kamu kurumları raporların 25 'inde $(\% 83,3)$, toplum 24 'ünde $(\% 80)$ ve medya/sosyal medya 22 'sinde $(\% 73,3)$ 
belirtilmiş, diğer paydaş gruplarını ise sırasıyla hissedar $(\% 63,3)$, yatırımcı $(\% 43,3)$, bayi/franchiser (\%40), eğitim kurumları $(\% 36,7)$, dağıtıcı $(\% 30)$, finans kuruluşları $(\% 26,7)$, iştirakler $(\% 26,7)$, rakipler $(\% 23,3)$, uluslararası organizasyonlar $(\% 20)$, sektörel dernekler (\%20), yerel yönetimler (\%20), düşünce liderleri (\%10), üniversite öğrencileri (\%10) ve sendikalar (\%10) oluşturmuştur. Sadece 1 firma çalışanların ailelerini paydaşları olarak belirlemiştir.

Tak (2009) çalışması temel alınarak aşağıda belirlenen paydaş gruplarının, incelenen 30 raporda geçme sıklığına göre bir değerlendirme yapılmıştır. Tablo 5 ile her bir paydaş grubu ve bu gruplarla eşdeğer kullanılan sözcüklerin 30 rapor ve 2617 sayfada geçme sıklığ sunulmuştur. İncelenen firmaların isimleri belirtilmemiş, faaliyet gösterdikleri sektörlere göre bir sınıflandırma yapılmıştır. Tüm paydaş gruplarının raporda geçme sıklığı 17183’tür. Raporlarda en çok belirtilen paydaş grubunun çalışanlar olduğu tespit edilmiştir. 5433 kez “çalışan” kelimesi geçmiştir. Bu paydaş grubunu 3679 kez ile “çevre” takip ederken "müşteri” kelimesi de $2882 \mathrm{kez}$ raporlarda yer almıştır. Tablo 4 ile de bağlantılı olarak incelenen firmalarda öne çıkan paydaş gruplarını özellikle “çalışan” ve “müşteriler”in oluşturduğu söylenebilir. En sık tekrarlanan diğer paydaş gruplarını sırasıyla; toplum, tedarikçi, medya, hissedar, STK, hükümet, dağıtıcı ve rakip oluşturmaktadır. Bu bulgular Tak (2009) ve Becan (2011) araştırma sonuçlarıyla da örtüşmektedir.

Sektörler bazında çok net ayrımlar yapılamamakla birlikte;

- “çalışan” sözcügünün sağllk sektöründe,

- “çevre” sözcügünün sağllk ve finans sektörlerinde,

- “müşteri” ve "hissedar” sözcüklerinin finans sektöründe,

- “tedarikçi” sözcüğünün otomotiv ve sağllk sektörlerinde,

- medya" sözcügünün enerji ve finans sektörlerinde, 
- "STK” ve "dağıtıcı" sözcüklerinin yiyecek-içecek sektöründe,

- "rakip" sözcügünün enerji sektöründe faaliyet gösteren firmalarda daha sık kullanıldığı tespit edilmişstir. 
Tablo 5:Paydaşlarla İlgili İçerik Analizi Bulguları

\begin{tabular}{|c|c|c|c|c|c|c|c|c|c|c|c|c|}
\hline Firma kodu & $\begin{array}{l}\text { Çalı } \\
\text { şan }\end{array}$ & $\begin{array}{l}\text { Çev } \\
\text { re }\end{array}$ & $\begin{array}{l}\text { Müşt } \\
\text { eri }\end{array}$ & $\begin{array}{l}\text { Pay } \\
\text { daş }\end{array}$ & $\begin{array}{l}\text { Topl } \\
\text { um }\end{array}$ & $\begin{array}{l}\text { Tedar } \\
\text { ikçi }\end{array}$ & $\begin{array}{l}\text { Med } \\
\text { ya }\end{array}$ & $\begin{array}{l}\text { Hisse } \\
\text { dar }\end{array}$ & $\begin{array}{l}\text { ST } \\
\text { K }\end{array}$ & $\begin{array}{l}\text { Hükü } \\
\text { met }\end{array}$ & $\begin{array}{l}\text { Dağı } \\
\text { tıcı }\end{array}$ & $\begin{array}{l}\text { Ra } \\
\text { kip }\end{array}$ \\
\hline ENERJI1 & 217 & 158 & 135 & 90 & 34 & 40 & 28 & 3 & 0 & 2 & 2 & 4 \\
\hline ENERJI2 & 189 & 158 & 149 & 82 & 69 & 35 & 23 & 4 & 3 & 1 & 0 & 4 \\
\hline ENERJI3 & 194 & 116 & 81 & 40 & 48 & 27 & 7 & 3 & 8 & 7 & 1 & 3 \\
\hline ENERJI4 & 132 & 140 & 37 & 51 & 63 & 13 & 6 & 4 & 6 & 10 & 1 & 0 \\
\hline FINANS1 & 210 & 286 & 241 & 81 & 34 & 29 & 17 & 20 & 3 & 6 & 0 & 0 \\
\hline FINANS2 & 357 & 169 & 325 & 68 & 89 & 20 & 34 & 34 & 11 & 11 & 0 & 0 \\
\hline FINANS3 & 189 & 178 & 240 & 55 & 76 & 8 & 7 & 23 & 8 & 5 & 0 & 0 \\
\hline FINANS4 & 38 & 91 & 39 & 33 & 65 & 2 & 21 & 2 & 10 & 3 & 0 & 0 \\
\hline FINANS5 & 85 & 168 & 50 & 54 & 33 & 30 & 9 & 17 & 11 & 6 & 0 & 0 \\
\hline FINANS6 & 144 & 120 & 255 & 89 & 63 & 19 & 6 & 29 & 0 & 11 & 0 & 1 \\
\hline FINANS7 & 165 & 64 & 162 & 64 & 28 & 7 & 15 & 12 & 4 & 2 & 0 & 0 \\
\hline GIDA1 & 245 & 142 & 26 & 92 & 65 & 70 & 1 & 6 & 24 & 8 & 48 & 0 \\
\hline GIDA2 & 85 & 30 & 50 & 34 & 5 & 31 & 10 & 5 & 1 & 2 & 0 & 0 \\
\hline GIDA3 & 65 & 49 & 6 & 17 & 20 & 15 & 2 & 0 & 3 & 1 & 5 & 0 \\
\hline HAVACILIK1 & 41 & 27 & 20 & 7 & 12 & 1 & 6 & 2 & 1 & 1 & 0 & 0 \\
\hline KIMYA1 & 121 & 73 & 29 & 20 & 18 & 19 & 1 & 5 & 0 & 0 & 0 & 0 \\
\hline LOJISTIK1 & 100 & 46 & 49 & 31 & 11 & 4 & 2 & 3 & 2 & 3 & 0 & 0 \\
\hline LOJISTIK2 & 145 & 73 & 67 & 97 & 157 & 31 & 10 & 1 & 8 & 12 & 0 & 0 \\
\hline OTOMOTIV1 & 404 & 156 & 208 & 64 & 83 & 51 & 7 & 3 & 2 & 4 & 8 & 0 \\
\hline OTOMOTIV2 & 169 & 128 & 72 & 51 & 44 & 57 & 16 & 4 & 1 & 5 & 0 & 2 \\
\hline OTOMOTIV3 & 117 & 186 & 61 & 36 & 28 & 125 & 5 & 9 & 5 & 2 & 0 & 0 \\
\hline SAGLIK1 & 438 & 219 & 73 & 80 & 128 & 89 & 13 & 14 & 3 & 8 & 1 & 1 \\
\hline SAGLIK2 & 166 & 175 & 18 & 32 & 30 & 14 & 0 & 1 & 10 & 5 & 0 & 0 \\
\hline SAGLIK3 & 411 & 117 & 24 & 80 & 98 & 103 & 1 & 1 & 12 & 2 & 0 & 1 \\
\hline SAGLIK4 & 46 & 36 & 18 & 18 & 38 & 10 & 5 & 5 & 5 & 1 & 1 & 0 \\
\hline TEKSTIL1 & 140 & 80 & 70 & 72 & 41 & 14 & 1 & 2 & 4 & 1 & 0 & 2 \\
\hline
\end{tabular}




\begin{tabular}{|c|c|c|c|c|c|c|c|c|c|c|c|c|}
\hline T.KOMUNIK & 162 & 37 & 119 & 36 & 27 & 25 & 8 & 5 & 4 & 5 & 0 & 1 \\
\hline \multicolumn{13}{|l|}{ ASYON1 } \\
\hline T.KOMUNIK & 233 & 112 & 141 & 47 & 68 & 95 & 17 & 15 & 9 & 6 & 0 & 1 \\
\hline \multicolumn{13}{|l|}{ ASYON2 } \\
\hline TUKETIM1 & 132 & 154 & 30 & 38 & 29 & 47 & 3 & 5 & 5 & 4 & 2 & 0 \\
\hline YAPI1 & 293 & 191 & 87 & 58 & 71 & 28 & 0 & 18 & 4 & 11 & 1 & 0 \\
\hline \multirow[t]{2}{*}{ TOPLAM } & 5433 & 367 & 2882 & 1617 & 1575 & 1059 & 281 & 255 & 16 & 145 & 70 & 20 \\
\hline & & 9 & & & & & & & 7 & & & \\
\hline \multirow[t]{2}{*}{$\%$} & 31,6 & 21, & 16,8 & 9,4 & 9,2 & 6,2 & 1,6 & 1,5 & 1,0 & 0,8 & 0,4 & 0,1 \\
\hline & & 4 & & & & & & & & & & \\
\hline
\end{tabular}

Tablo 6 ile incelenen 30 firmanın sürdürülebilirlik ve KSS raporlarında paydaş katılımına ilişkin bulgular sunulmaktadır. Raporların 29'unda ve \%96,7'sinde paydaş katılımı için ayrı bir bölüm oluşturulmuştur. Raporların 11'inde “paydaş katılımı”, 7'sinde “paydaşlarla iletişim", 6'sında "paydaşlarımız" bölümlerine yer verilmiş, diğer raporların her birinde “paydaşlar, paydaşlarla iletişim ve önceliklendirilen konular”, "paydaşlarımız ve iletişim yöntemleri”, “paydaş beklentileri yönetimi”, “paydaşlarla ilişkilerimiz” ve "paydaş ilişkileri yönetimi” başlıklı bölümler oluşturulmuştur.

Raporların tümünde paydaş katılımının stratejik hedeflerin belirlenmesi ve değerlendirilmesinde yer aldığı belirtilmiş, 27 raporda (\%90), rapor içeriğinin belirlenmesinde paydaşların etkin rol aldığı tespit edilmiştir.

Paydaşların raporlarda temsil edilme düzeylerine bakıldığında; 27 raporda (\%90), raporlama sürecinde faaliyet gösteren paydaş gruplarına ilişkin bilgilerin sunulduğu görülmüştür. Seçilen paydaş gruplarının firmaların sürdürülebilirlik raporlarının oluşturulması sürecindeki rolleri belirtilmiştir. 
Paydaş katılımlarının düzeyi açısından ise, raporların tümünde paydaşların rapor içeriği konusunda danışma, gözetim ve bilgi sağlama rolünün olduğu belirtilmiştir. Ancak, paydaşların raporlama sürecinde doğrudan katılım sağladığına ilişkin bilgi sunan sadece 19 firma $(\% 63,3)$ olduğu görülmüştür. Paydaşların, raporlama sürecine başından beri çeşitli etkinlikler ve iletişim yöntemleriyle dâhil olduğu konusunda bilgi veren firma sayısı ise 21 (\%70)'dir. Paydaşların, sürdürülebilirlik ve KSS raporlarının son hallerinin gözden geçirilmesi aşamasına dâhil oldukları bilgisini raporlarında belirten firma sayısı ise 21 (\%70)'dir. 23 firma $(\% 76,7)$ paydaşların bir önceki rapora ilişkin eleştirilerini dikkate alarak yeni raporu hazırladıkları bilgisini verirken sadece 18 firma (\%60), paydaşlarının raporda sunulan bilgilerin önemlilik ve güvenilirliğini değerlendirmelerini istediğine dair bilgiyi raporlarında sunmuştur.

1 firma dışında tümü (29 firma, \%96,7), “GRI.4.16. Paydaş türü ve grubuna göre katılım sıklığı da dâhil paydaş katılımı yöntemleri” kapsamında sunulması beklenen, paydaş katılımını sağlamada kullandıkları iletişim kanallarını ve yöntemlerini paydaş grubuna göre ayrıntılı olarak belirtmiştir. Paydaşlarla iletişim yöntemlerinden bazıları; internet, konferans ve seminerler, paneller, çalıştaylar, eğitim faaliyetleri, müşteri memnuniyet anketleri, çalışan katılımı anketleri, işletme raporları, ziyaretler, üyelikler, proje ortaklıkları ve sosyal kampanyalardir.

Paydaş katılımı konusunda çoğunlukla olumlu kısımların raporlarda ele alındığı görülmüştür. Paydaş katılımı konusunda karşılaşılan güçlükler sadece 6 raporda (\%20) belirtilmiştir. Raporların 16'sında (\%53,3), raporlama sürecine paydaş katılımında AA1000SES ve Avrupa Kalite Yönetimi Vakfı (EFQM) Mükemmellik Modeli gibi belirli prensiplerin kullanıldığı belirtilmiştir. Raporlarında, kaliteli paydaş katılımının tasarımı, uygulanması, değerlendirilmesi ve iletişimini oluşturan genel kabul görmüş çerçeve sunan bir standart olan 
(AccountAbility, 2008) AA1000 Paydaş Katılımı Standardı'nı kullandıklarını belirten firmaların sayısı sadece $9(\% 30)$ 'dur.

Raporlarında sürdürülebilirlik konuları matrisi veya önceliklendirme matrisine (SustainabilityIssues/MateralityMatrix) yer veren firmaların sayısı ise sadece $10(\% 33,3)$ 'dur. Beklenildiğinin aksine önceliklendirme matrisinin yer aldığı raporların GRI uygulama seviyeleri farklılık göstermektedir. 
30 Yrd. Doç. Dr. Çimen KARATAŞ ÇETIN ,Yrd. Doç. Dr. Seçil VARAN,Araş. Gör. Cemile SOLAK FIŞKIN

Tablo 6:Sürdürülebilirlik ve Kurumsal Sosyal Sorumluluk Raporlarında Paydaş Katılımı

\begin{tabular}{|c|c|c|}
\hline 1.PAYDAŞ KATILIMI BÖLÜMÜ & $\begin{array}{l}\text { Firma sayısı } \\
\text { (n) }\end{array}$ & $\%$ \\
\hline 1.1.Raporda "paydaş katılımı" için ayrı bir bölüm mevcut mu? & 29 & 96,7 \\
\hline \multicolumn{3}{|l|}{ 1.2.Paydaş katılımının amaç ve hedefleri } \\
\hline -stratejik hedeflerin belirlenmesi veya gözden geçirilmesi & 30 & 100,0 \\
\hline -rapor içeriğinin belirlenmesi (hangi bilgilerin karar verme sürecinde önemli olduğu) & 27 & 90,0 \\
\hline
\end{tabular}

\section{PAYDAŞLARIN TEMSIL EDILME DÜZEYI}

2.1.Raporlama sürecine katılan paydaş grupları arasından temsilciler atanmış mı?

\section{PAYDAŞ KATILIMININ DÜZEYI}

3.1.Danışma, gözetim ve bilgi sağlama

3.2.Raporlama sürecinde doğrudan katılım

19

63,3

3.3.Raporlama sürecine başından beri dahil olma

3.4.Son raporun gözden geçirilmesine dahil olma

3.5.Paydaşların önceki raporlara ilişkin eleştirilerinin dikkate alınması

3.6.Paydaşların raporda sunulan bilgilerin önemlilik ve güvenilirliğini değerlendirmelerinin istenmesi

\section{PAYDAŞ KATILIMI KANALLARI VE YÖNTEMLERİ}

4.1.Paydaş katılımı kanalları ve yöntemleri belirtilmiş mi?

\section{PAYDAŞ KATILIMINA İLIŞSKIN KONULAR}

5.1.Paydaş katılımı konusunda karşılaşılan güçlükler belirtilmiş mi?

\section{6}

20,0

5.2.Paydaş katılımı için spesifik prensipler kullanılmış mı?

16

53,3

5.3.AA1000 Paydaş Katılımı Standardı kullanılmış mı? 9

30,0

5.4.Raporda sürdürülebilirlik

konular

veya

önceliklendirme

matrisine

10

33,3

(SustainabilityIssues/MateralityMatrix) yer verilmiş mi? 
Tablo 7 ile 30 raporun GRI G3.1 Paydaş Katılımı Göstergelerini Raporlama durumu sunulmaktadır. Firmaların sürdürülebilirlik ve KSS raporlarının son sayfalarında GRI Endeksi bölümünde verilen bu tabloların incelenmesi sonucu GRI.4.15. ve GRI.4.17. göstergelerinin 1 firma (C düzeyi) tarafından kısmen raporlandığı görülmüştür. GRI Uygulama Seviyesi C olan 2 firma ise GRI.4.16. ve GRI.4.17 için herhangi bir raporlama bilgisi vermemiştir. Bunun nedeni, bu iki göstergenin C seviyesi için listelenen ölçütler arasında yer almaması ve dolayısıyla bu firmaların bu ölçütlerde raporlama yapma zorunluluklarının olmamasıdır. Bahsedilen 3 firma dışında tüm firmaların raporlarında GRI G3.1 Paydaş Katılımı Göstergelerini Raporlama Durumunun tam olduğu saptanmıştır.

Tablo 7: GRI G3.1 Paydaş Katılımı Göstergelerini Raporlama Durumu

\begin{tabular}{lccc}
\hline GRI G3.1 Paydaş Katılımı Göstergelerini Raporlama Durumu & Tam & Kısmen & Belirtilmemiş \\
\hline GRI.4.14. Kurum tarafından katılımı sağlanan paydaş gruplarının listesi & 30 & 0 & 0 \\
GRI.4.15. Katılım yapılacak paydaşların kimler olacağının belirlenmesi ve & 29 & 1 & 0 \\
seçimlerine dair esas & & 2 \\
GRI.4.16. Paydaş türü ve grubuna göre katılım sıklığı da dâhil paydaş 28 & 0 & 2 \\
katılımı yöntemleri & & 1 \\
GRI.4.17. Paydaş katılımı ile ortaya konan başlıca konular ile kaygılar ve & 27 & 2 \\
kurumun bunlara, yaptığı raporlama aracılığıyla verdiği yanıt da dâhil & & \\
nasıl yanıt verdiği & & \\
\hline
\end{tabular}

Genel bir değerlendirme yapmak gerekirse, her ne kadar raporlama durumları tam olarak belirtilmiş olsa da firmaların birçoğu sürdürülebilirlik ve KSS raporlarında paydaş gruplarını saptayarak (GRI.4.1.4), paydaş grubuna göre iletişim yöntemlerini (GRI.4.16) belirtmişlerdir. Bunun dışında katılım yapılacak paydaşların nasıl belirlendiği ve paydaş katılımı sonucunda öne çıkan konular ve kaygılara çok yer verilmediği anlaşılmıştır. Daha önce de belirtildiği 
gibi, paydaşlarla iletişim sonucu öne çıkan konuları içeren önceliklendirme matrisleri çok az sayıda firma tarafından bir paydaş katılımı aracı olarak kullanılmıştır.

\section{TARTIŞMA VE SONUÇ}

Paydaş katılımı, sürdürülebilirlik raporlamasında kilit rol oynamaktadır. GRI rehberlerinde,işletme ile ilgili sadece olumlu açıklamalar sunan sürdürülebilirlik raporlarının yerini, paydaş katılımı ile önceliklendirilmiş bilgilerin açıklandığı raporların alması gerektiği belirtilmektedir.

Paydaş teorisi araştırmacılarına göre; paydaş katılımı, işletmenin tüm paydaşlar için değer yaratma amacına ulaşmasında önemli bir araçtır. Bu aracın etkin kullanımı, işletmeler ve tüm paydaşlar için fayda sağlayacaktır. Bu nedenle bu araştırma, Türkiye'de faaliyet gösteren firmaların sürdürülebilirlik raporlamasında bu aracı ne derece etkin kullandıklarını analiz etmektedir.

Araştırmanın bulgularına göre, incelenen işletmelerin sürdürülebilirlik raporlarında paydaşlarla ilgili yapılan açıklamaların paydaş katılımından ziyade, paydaş yönetimi temelli olduğu ortaya çıkmıştır. Paydaşların nasıl belirlendiği konusuna ve paydaş katılımı sonucunda öne çıkan konulara, karşılaşılan güçlüklere, kaygılara ve olumsuzluklara az sayıda firmanın yer verdiği görülmüştür. Paydaşlarla iletişim sonucu öne çıkan konuları içeren “önceliklendirmematrisleri”nin azlığı bu durumun bir göstergesidir. Bu bulgular, Manetti (2011) ve Manetti ve Toccafondi (2014) ile tutarlıdır.

Sürdürülebilirlik raporları birçok ülkede "gönüllülük” esasına göre hazırlanan raporlardır. Bu raporların içerikleri, tüm paydaşlara olan faydaları nedeniyle, ekonomik ve sosyal açıdan, ayrıca çevre açısından önemlidir. Türkiye'deki literatürde sürdürülebilirlik raporlarında paydaş katılımı konusunda yeterince çalışmaya rastlanmaması nedeniyle, konu hakkında bir başlangıç çalışması olarak değerlendirilebilmesi, araştırmanın bilimsel katkısını oluşturmaktadır. Araştırmanın uygulamadaki katkısı ise, Türkiye'de sürdürülebilirlik 
raporlarını hazırlama süreçlerinde paydaş katılımı uygulamalarının hangi konularda yetersiz kaldığının ve bu süreçte nelere odaklanılması gerektiğinin sunulmasıdır.

Araştırmanın temel kısıtları; 2012-2013 y1lları arasında GRI standartlarına uygun olarak sürdürülebilirlik ve kurumsal sorumluluk raporları hazırlayan ve Türkiye'de faaliyet gösteren firma sayısının az olması ve dolayısıyla örneklemin sınırlı kalmasıdır. Bu nedenle de örneklemin belirlenme sürecinde GRI Uygulama Seviyesine göre bir sınırlandırma getirilememiştir. İleriki yıllarda GRI internet sitesinden erişilebilir rapor sayısının arttırılması ile daha geniş kapsamlı incelemelerin yapılabileceği düşünülmektedir. Bunun yanında araştırmada yöntem olarak raporların incelenmesi amacıyla içerik analizi teknikleri kullanılması ve incelenen firmaların paydaş katılımı konusundaki görüş ve önerilerinin alınmaması yöntemsel olarak bir sınırlama olarak değerlendirilebilmektedir. Araştırmanın kısıtlarına paralel olarak gelecek araştırmalar için öneriler, Türkiye ile sınırlı kalmayıp dünya genelinde sektörel değerlendirmelerin yapılması ve içerik analizi tekniğinin yanı sıra nicel araştırmalarla da bulguların test edilmesidir.

\section{KAYNAKÇA}

Account Ability (2008), AA1000 Stakeholder Engagement Standard 2011, Final Exposure Draft, www.accountability.org, (Erişim Tarihi:07.12.2014).

Altuntaş, C. ve Türker, D. (2012). "Sürdürülebilir Tedarik Zincirleri: Sürdürülebilirlik Raporlarının İçerik Analizi”Dokuz Eylül Üniversitesi Sosyal Bilimler Enstitüsü Dergisi, 14(3):39-64

Becan, C.(2011). "Kurumsal Sosyal Sorumluluk Kavramının Paydaş Teorisi ve İletişim Yaklaşımı Acısından Değerlendirilmesi: Bankaların Basın Bültenlerine Yönelik Bir İçerik Analizi”Selçuk Illetişim Dergisi, 7(1):16-35.

Belal, A. (2002). "Stakeholder accountability or stakeholder management: a review of UK firms' social and ethical accounting, auditing and reporting (SEAAR) practices" Corporate Social Responsibility and Environmental Management, 9(1): 8-25.

Belal, A. R. ve Owen,D.L. (2007). "The views of corporate managers on the current state of, and future prospects for, social reporting in Bangladesh" Accounting, Auditing \&AccountabilityJournal, 20(3): 472-494. 
Bilgin, N. (2006). "Sosyal Bilimlerde İçerik Analizi: Teknikler ve Örnek Çalışmalar", Ankara, Siyasal.

Evliyaoğlu, F. ve Hemedoğlu, E. (2012). "Toplam Kalite Yönetimi Uygulamalarının Finansal Olmayan Performans Algısı Üzerindeki Etkileri” İşletme Araştırmaları Dergisi,4(3):127-147.

Freeman, R.E.(1984). “Strategic Management: A Stakeholder Approach”, Boston, Pitman. Freeman, R.E. ve Reed, D.L. (1983). "Stokholders and Stakeholders: A New Perspective on Corporate Governance.” California Management Review,25(3): 88-106.

Gable, C. ve Shireman, B. (2005). "Stakeholder Engagement: A three-phase Methodology" Environmental Quality Management, 14(3):9-24.

Gökçe, O. (2006). “İçerik Analizi: Kuramsal ve Pratik Bilgiler”, Ankara, Siyasal.

Greenwood, M. (2007). "Stakeholder Engagement: Beyond the Myth of Corporate Responsibility” Journal of Business Ethics, 74(4):315-327.

GRI (2010), https://www.globalreporting.org/reporting/G3andG3-1/g3-1guidelines/Pages/default.aspx, (Erişim Tarihi:08.12.2014)

GRI (2011), https://www.globalreporting.org/reporting/G3andG3-1/g3-1guidelines/Pages/default.aspx, (Erişim Tarihi:08.12.2014)

GRI (2014), https://www.globalreporting.org/resourcelibrary/Turkish-G4-Part-One.pdf, (Erişim Tarihi:08.12.2014)

Gürol,Y.,Büyükbalc1, P., Bal, Y. ve Ertemsir Berkin, E. (2010) "Kurumsal Sosyal Sorumluluk Kavramı ve Gelişmekte Olan Ülkelerde Konuya Bakış” İ.Ü. Siyasal Bilgiler Fakültesi Dergisi, 43:135-162.

KPMG (2008), Sustainability Reporting: A Guide, 2008, http://www.kpmg.com/cn/en/issuesandinsights/articlespublications/pages/sustainable-guide200811.aspx, (08.12.2014)

Longo, M.,Mura, M. ve Bonoli, A. (2005). "Corporate Social Responsibility and Corporate Performance: The Case of Italian SMEs” CorporateGovernance, 5(4):28-42.

Manetti, G. (2011). "The Quality of Stakeholder Engagement in Sustainability Reporting: Empirical Evidence and Critical Points"Corporate Social Responsibility and Environmental Management, 18(2):10-122.

Manetti, G. ve Toccafondi, S. (2014). "Defining the Content of Sustainability Reports in Nonprofit Organizations: Do Stakeholders Really Matter?"Journal of Nonprofit \& Public Sector Marketing, 26(1):35-61.

Mathis, A. (2007). "Corporate Social Responsibility and Policy Making: What Role Does Communication Play?” Business Strategy and the Environment, 16(5):366-385. 
Mio, C. ve Venturelli, A. (2013). "Non-financial Information about Sustainable Development and Environmental Policy in theAnnual Reports of Listed Companies: Evidence from Italy and the UK" Corporate Social Responsibility and Environmental Management,20(6):340358.

Moneva, J.M.,Rivera-Lirio, J.M. ve Muñoz-Torres, M. J. (2007). "The corporate stakeholder commitment and social and financial performance", Industrial Management \& Data Systems, 107(1):84-102.

Özalp, İ.,Tonus, Z. ve Sarkaya, M. (2008). "İktisadi ve İdari Bilimler Fakültesi Öğrencilerinin Kurumsal Sosyal Sorumluluk Algılamaları Üzerine Bir Araştırma” Anadolu Üniversitesi Sosyal Bilimler Dergisi,8(1):69-84.

Özdaşl1, K. ve Çelikkol, Ö. (2012). "Psikolojik Sözleşme: Kavramsal Çerçeve ve Bir İçerik Analizi” Mehmet Akif Ersoy Üniversitesi Sosyal Bilimler Enstitüsü Dergisi,4(7):141-154.

Prado-Lorenzo,J.M.,Gallego - Alvarez, I. ve Garcia - Sanchez, I.M. (2009). "Stakeholder Engagement and Corporate Social ResponsibilityReporting: the Ownership Structure Effect" Corporate Social Responsibility and Environmental Management, 16(2): 94-107.

Preble, J. F. (2005).“Toward a Comprehensive Model of Stakeholder Management” Business andSocietyReview, 110(4):407-431.

Quinn, L. ve Dalton, M. (2009). "Leading for sustainability: Implementing the tasks of leadership" Corporate Governance: The international journal of business in society, 9(1):2138 .

Skouloudis, A.,Evangelinos, K. ve Moraitis, S. (2012). "Accountability and Stakeholder Engagement in theAirport Industry: An Assessment of Airports' CSR Reports" Journal of Air Transport Management, 18(1):16-20.

Tak, B. (2009). "İşletmelerin Sosyal Sorumlulukları ve Paydaş Grupları ile İlişkilerinin Yönetimi”, İstanbul, Beta.

Temizel, F., Sarıkaya, M. ve Bayram, F. (2010). "Yatırımcı İlişkileri Yönetiminde İletişim Ve Bilgi Teknolojilerinin Rolü: İMKB 50 Endeksi Uygulaması"Atatürk Üniversitesi İktisadi ve Ídari Bilimler Dergisi, 24(2):1-20.

Ulusan, H. (2009). "Çevresel Raporlama Rehberleri ve İşletme Çevresel Raporlarında Açıklanması Gereken Bilgiler"Süleyman Demirel Üniversitesi İktisadi ve İdari Bilimler Fakültesi Dergisi, 14(2):181-206.

Van Huijstee, M. ve Glasbergen, P. (2008). "The practice of stakeholder dialogue between multinationals and NGOs" Corporate Social Responsibility and Environmental Management, 15(5): 298-310.

Wimmer, R. D. ve Dominick, J. R. (2000). "Mass Media Research: An Introduction", Belmont: Wadsworth Publishing Company. 